\title{
UMA ANÁLISE SOBRE A CONTRIBUIÇÃO DO SETOR INDUSTRIAL PARA O CRESCIMENTO ECONÔMICO E SOCIAL DO PARANÁ
}

\author{
Rodrigo Monteiro da Silva* \\ Greicy Maria Milane Fim Dobler**
}

RESUMO: O setor industrial possui papel de grande destaque para a geração de desenvolvimento econômico e social em um país, visto que esse setor exerce expressivo impacto regional dado sua capacidade de gerar externalidades positivas para todas as atividades a sua volta, tanto a jusante como a montante, estimulando desse modo melhora de indicadores não somente econômicos, mas também sociais. No caso brasileiro, o setor que sempre foi considerado essencial, e por isso desde sua colonização considerado prioritário pelas políticas nacionais foi a agricultura, enquanto que a indústria, apenas em 1930, começa a ser alvo de políticas por parte do governo, em nível nacional e estadual. Entre os Estados da região Sul, o Paraná tem tido destaque industrial, com níveis de crescimento acima do nacional. Dessa forma, dado o presente cenário, a presente pesquisa objetivou analisar qual tem sido o desempenho da indústria do Estado entre os anos de 2005 e 2015. A metodologia empregada foi de caráter estatística descritiva e também bibliográfica. Os resultados mostram um bom desempenho da indústria, principalmente em termos de geração de emprego e renda, impulsionando dessa forma o crescimento e desenvolvimento econômico paranaense.

PALAVRAS-CHAVE: Indústria paranaense; Indústria de transformação; Crescimento socioeconômico.

\section{THE INDUSTRIAL SECTOR' $S$ CONTRIBUTION TOWARDS ECONOMIC AND SOCIAL GROWTH IN THE STATE OF PARANÁ}

ABSTRACT: The industrial sector has the role of producing economic and social development in the country since it exerts a highly dense regional impact. In fact, it generates positive external things for all activities, above and below, and stimulates improvement in economic and social indexes. The sector has always been considered

\footnotetext{
* Mestrando em Teoria Econômica pela Universidade Estadual de Maringá (UEM), Brasil.

E-mail: rodrygomsylva@gmail.com

** Bacharel em Ciências Econômicas pela Universidade UNOPAR, Brasil.
} 
basic in Brazil. In colonial times, priority was given to the agricultural sector, whilst industry became the government's target since the 1930s at national and state levels. Among the southern states, the state of Paraná has always had industrial trends, with growth above national averages. Current research analyzes the performance of the state's industry between 2005 and 2015 through a methodology involving descriptive and bibliographic statistics. Results show good performance, especially in the generation of vacancies and earning, which triggers economic growth and development in the state of Paraná.

KEY WORDS: Parana industry; Transformation industry; Socioeconomic growth.

\section{INTRODUÇÃO}

Ao se analisar o modo como um país produz seus bens e serviços verificase uma distinção entre setores, sendo que tal definição se dá pelo tipo de produto criado. Esses setores são três, sendo eles o primário, secundário e terciário, definidos como agrícola, indústria e serviços, respectivamente. Saber como se dá o funcionamento, bem como a divisão deles dentro de uma economia é um meio de se verificar qual o seu nível de crescimento econômico, dado que são eles os responsáveis pelo PIB nacional.

Dentre os três setores existentes, a indústria se destaca por ter grande potencial de agregação de valor e ter grande influência em outras áreas, ou seja, um setor que impacta diretamente diversas outras atividades que não são necessariamente ligadas a ela. Uma nação com uma indústria forte tem por consequência um processo produtivo mais eficiente, com custos menores, melhores produtos, o que gera maior visibilidade de mercado frente a concorrência tanto em nível nacional como internacional. Das diversas externalidades criadas por esse setor, como seu poder de impulsionar outras atividades, por exemplo, demanda por insumos a jusante, melhoria nos meios de escoamento da produção (rodoviário, ferroviário, hidroviário) geração de emprego e renda (que estimula um conjunto de atividades para suprir as necessidades desses trabalhadores assalariados como consumo, vestuário, construção civil, etc.) o processo inovativo é um dos mais importantes, uma vez que este no ambiente produtivo necessita de profissionais 
com maior nível de qualificação, o que fomenta em nível nacional a melhoria da educação para que essa demanda seja atendida.

Dessa forma, dada a importância desse setor, a presente pesquisa teve como objeto de estudo a indústria, especificamente para o Paraná, a fim de verificar como ela influenciou melhorias em aspecto econômicos e sociais do Estado. A escolha da temática se justifica pela importância do setor para a melhoria nos indicadores de crescimento socioeconômico estadual. Assim, o que foi analisado, entre os anos de 2005 a 2015, foi a participação da indústria na geração de emprego, renda, e crescimento econômico do Paraná.

A pesquisa foi dividida em quatro seções, além dessa Introdução. A próxima seção aborda o processo de histórico de desenvolvimento do setor industrial paranaense, verificando quais foram seus determinantes, e também quais foram as políticas adotadas ao longo das últimas décadas. A segunda seção apresenta a metodologia que foi empregada para se alcançar o objetivo proposto pelo trabalho, seguido da seção que apresenta os resultados da pesquisa e das considerações finais.

\section{REFERENCIAL TEÓRICO: FORMAÇÃO HISTÓRICA DA INDÚSTRIA PARANAENSE}

O processo de formação da indústria paranaense se deu por volta do século XIX, tendo como principal atividade a produção ervateira, seguido da extração de madeira e do café (TRINTIN, 2006). De acordo com Loeffler (2009) a produção de mate no Estado era por empresas de pequeno porte, com pouca complexidade industrial e um processo produtivo com reduzida mecanização.

Não obstante a esse fato, de acordo com Verri (1998) e Naldony (2014), mesmo sendo de porte pequeno e baixa complexidade industrial, a erva mate foi vital para o processo de industrialização do Estado, uma vez que ela foi o primeiro produto paranaense a obter comércio regional, nacional e internacional, sendo exportada para países como Argentina, Uruguai e Paraguai. O bom desempenho desse produto motivou o início de um plano de melhoria na infraestrutura paranaense, a exemplo da melhoria de rodovias, como foi o caso da construção da estrada da Graciosa, em 1873 (BÔAS, 2011; LOEFFLER, 2009). 
O próximo produto com grande destaque no cenário estadual foi a extração de madeira. Verri (1998) aponta que esse produto se desenvolveu primeiramente como uma atividade secundária em relação à indústria ervateira, suprindo a demanda desse setor por, principalmente, embalagens, e conforme crescia o desenvolvimento dos centros urbanos a extração madeireira começa a se destacar pelo concomitante crescimento da demanda desse bem pelas novas cidades. O principal fator de impacto negativo na produção do mate paranaense foi a política de substituição de importações que os países que mais demandavam esse produto, Argentina e Uruguai, adotaram, que levou a políticas restritivas de importação da erva mata brasileira, a partir de 1931. Esse fato fez com que o impulso industrial do Estado se volta para a atividade de extração (NIEHUES, 2014).

No entender de Niehues (2014), o que salvou a economia do Estado, mesmo em um cenário de crise externa, nas décadas de 1930 e 1950, foi o setor cafeeiro. Das diversas contribuições desse commodities para a indústria do Estado foi a dispersão e ocupação do norte, com o grande contingente de mão de obra que começaram a trabalhar nas plantações de café, especificamente após 1940.

$\mathrm{O}$ impulso provocado pelo café foi responsável pela dinamização da indústria, que a partir desse momento começa a apresentar crescimento constante. Fato é que a indústria começou a ter taxas de crescimento maior mesmo que a própria agricultura, com média de crescimento de $7,7 \%$ nesse período, maior que 0 agrícola, que teve crescimento médio de 4,9\% no mesmo período (NIEHUES, 2014; TRINTIN, 2006). Dessa forma, ao se analisar os primórdios da industrialização no Estado, o que se verifica foi uma transição entre três principais produtos agrícolas, que demandavam bens industriais. Nesse processo, entre erva-mate, extração de madeira e café, esse último foi o que permitiu, por diversos fatores, o impulso necessário para que se formasse no Estado o primeiro esboço do que seria um parque industrial que era voltado para a torrefação e moagem, e também a confecção de sacas para se utilizar no armazenamento (VERRI, 1998).

A história da industrialização paranaense se deu como atividade secundária, servindo como meio de suprimento de produtos demandados por atividades agrícolas, sem que houvesse, pelo menos não de início, algum plano ou projeto prévio, com total inexistência de recursos e investimentos de capitais públicos ou 
privados. Esse cenário só muda após a década de 60, quando é criada a Companhia de Desenvolvimento do Paraná (CODAPAR), que em essência tinha por objetivo um meio de estimular o desenvolvimento industrial paranaenses (MIGLIORINI, 2006).

No entender de Trintin (2006), o importante papel que o café tinha para a economia do Estado, e dada a incipiente de sua infraestrutura industrial, o governo começa a se atentar para essa situação em que sua economia se encontra, dada a baixa produtividade de produtos com elevados valor agregado e a inconstância do mercado externo em termos de preço e demanda do café. Dessa forma, no 1960, se verifica um notório desenvolvimento industrial no Paraná, com criação e melhorias em setores chaves para a indústria, como melhorias na oferta de energia elétrica, construção de ferrovias, expansão da quantidade de navios que poderiam ter acesso ao porto de Paranaguá e melhoria no sistema de comunicação, fatos esses que contribuíram para impulsionar o surgimento do setor industrial do estado (MIGLIORINI, 2006; LOURENÇO ,2003). No fim da década de 1960, o café começa a apresentar sinais de esgotamento em termos de retornos, por motivos relacionados principalmente a fatores climáticos como também as políticas que foram adotadas para diversificar a produção agrícola. É nesse ambiente de mudanças que outro produto agrícola ganha grande notoriedade, a saber, a soja (TRINTIN, 2006).

A soja, por ser um produto que surgiu em um momento em que já se havia certa mecanização agrícola, e dado suas características próprias, gerou outra onda de êxodo rural, uma vez que a necessidade de poucos trabalhadores gerou uma maciça transição da população antes empregada no café para as cidades. Sendo esse um fator necessário (crescimento da população urbano) para o desenvolvimento da indústria (não obstante, suficiente) propiciou grande quantidade de trabalhadores que agora poderiam ser empregados em atividades com maior complexidade produtiva que a agrícola, sendo que o que ocorreu em seguida ao êxodo rural foi a presença de atividades relacionadas ao processamento da soja, especificamente na produção de farelo e óleo (OLIVEIRA, 2001; NIEHUES, 2014).

De acordo com dados do IPARDES (1987), no ano de 1970 o Paraná já apresenta uma indústria com considerável grau de modernidade tecnológica para época. Fato é que a indústria cresceu em aproximadamente $17 \%$, que se deve ao fato da grande diversificação industrial, com o surgimento de indústrias com atividades 
em material elétrico, químico e automobilístico. Esse processo fez com que mesmo o café tivesse redução na participação do produto do Estado sofresse redução, indo de 54\% em 1970 para 35\% em 1979.

Já na década de 1970, o Estado, com uma cooperação da Federação de Indústrias do Paraná (FIEP) e da Associação Comercial do Paraná (ACP), propôs a tentativa de maior integração com a União, com pedido de apoio para investimentos nos setores industriais de siderurgia e também no petroquímico. A ACP também foi responsável por uma conferência, no ano de 1971, trazendo a proposta de elaboração do primeiro seminário de desenvolvimento industrial. Dessa conferência teve como um dos resultados a criação de uma política de fomento à indústria baseado em parceria com bancos de fomento e maior cooperação intra e interindustrial (OLIVEIRA, 2001).

No entender de Trintin (2006), essa diversificação que ocorreu por fatores políticos desencadeou uma reestruturação dos produtos industriais produzidos no estado, uma vez que o aumento de tecnologia trouxe maior valor agregado, o que gerou ganhos de produtividade, de eficiência, aumento a competitividade no mercado interno e externo do Estado. Dentro dessa nova reestruturação algumas regiões do Estado se destacaram, entre elas a região Metropolitana de Curitiba foi a maior, que teve o surgimento e crescimento industrial em atividades do complexo cimenteiro, metalomecânico e refino de petróleo.

Nessa região surgiu a denominada Cidade Industrial de Curitiba, doravante CIC, que foi lar de empresas que refinavam petróleo e da Volvo, que se alocaram na região pelas políticas de fomento a industrialização. Tão forte foi esse processo na CIC que ela foi responsável pela atração de novos capitais, privados, estrangeiros, o que geraram novos incentivos fiscais, o que solidificou ainda mais essa região como a mais industrializada do Estado, realidade essa que se estende até os dias de hoje (LOURENÇO, 2003; TRINTIN, 2006).

Como o movimento de industrialização tem por características levar a dinamização de todos os outros setores da economia, fato é que o boom industrial teve reflexos na agricultura, dadas as melhorias no maquinário destinada à produção, ao cultivo e à colheita, fez que com as culturas, como a soja e o milho, tivessem seus resultados de safras exponenciadas, gerando grande cadeia intersetorial que veio a se 
tornar nas décadas recentes à cadeia agroindustrial paranaense (MIGLIORINI, 2006).

De modo geral, o processo de industrialização no Estado foi semelhante ao nacional, em que um conjunto e fatores internos e externos, não planejados, deram o impulso para que a indústria se desenvolvesse, mesmo que de modo tenro e, com o tempo, o poder público começa a perceber a necessidade de um estrutura industrial forte, para garantir o crescimento econômico daquela região. No Paraná, a agroindústria teve grande destaque, uma vez que os investimentos para aumento da demanda interna e externa, a modificação produtiva impactou positivamente uma mais inovação, sendo que as atividades relacionadas a carne, notadamente a industrializada, o café solúvel, os óleos vegetais e os laticínios foram os que mais se tiveram crescimento por meio das estruturais, que fez com que se tornassem os principais produtos do Estado, com cada vez mais destaque na economia brasileira.

Em uma análise mais recente, de acordo com a Federação das Indústrias do Estado do Paraná (FIEP), em pesquisa realizada em (2015) o Paraná possui destaque em seu nível industrial em termos de Brasil, visto que ocupa a quarta posição brasileira em número de empregos e estabelecimentos, sendo a maior parte desse número a atividades relacionadas a alimentos, veículos \& carrocerias, construção, vestuário \& acessórios.

Em termos de produção, o PIB industrial do Estado detém a quinta colocação nacional, já que, além de possuir grande mercado interno, o Paraná tem apresentando crescimento em sua participação na quantidade de bens industrias exportados, tendo na China, Argentina e Alemanha seus principais mercados consumidores. Em termos regionais, a região Metropolitana de Curitiba é a que possui o maior número de municípios com maior participação PIB do Estado. Já regiões próximas a outros dois grandes centros, Londrina e Maringá, são mais voltadas à agroindústria, e já a parte litorânea do Paraná são dedicadas as atividades portuárias (FIEP, 2015; IPARDES, 2010).

Em 2012, a indústria de transformação e extração paranaense venderam $\mathrm{R} \$$ 181,8 bilhões, um total de $8,7 \%$ vendas industriais do Brasil no mesmo ano, sendo que o total produzido foi de quase $8 \%$ do nacional, o quinto maior valor em termos de Estado. Já para o valor adicionado da indústria, ainda em, 2012, o Paraná gerou $\mathrm{R} \$ 68,8$ bilhões, ocupando a posição de quarto Estado com maior geração do valor 
adicionado, vale destacar que alimentos e veículos \& carrocerias foram as que mais contribuíram para esses resultados, já que somaram $44 \%$ da produção industrial e $40 \%$ do valor adicionado industrial, sem considerar que foram responsáveis pelo aumento de mais de $60 \%$ das exportações e em 35\% dos empregos entre os anos de 2007 e 2013 (FIEP, 2015).

Borges (2015) aponta que o comportamento da produção da indústria do Estado foi de crescimento médio acima da média do país, e esse fato se deu por maior dinamicidade em questões relacionadas ao crescimento de produção de bens de capital e de bens de consumo duráveis, aliado a melhora nas atividades de processamento do petróleo e outros, como o etanol, produtos têxteis e alimentos. Ainda de acordo com Borges (2015) nos anos de 2008 a 2012, a indústria do Estado apresentou aumento acumulado de aproximadamente $13 \%$, valor esse menor que nos anos anteriores, em que em 2004 a 2008, apresentou crescimento de quase 167\%. A possível explicação para esse resultado foi a crise financeira internacional que ocorreu no período.

Em 2008, com a crise financeira, houve acentuada redução do crédito estrangeiro, desvalorização cambial, diminuição de investimentos, dos preços das commodities e da atividade econômica que, consequentemente, gerou queda nos resultados da indústria e da agropecuária. A retração industrial nos anos de 2004 e 2008, ao se comparar com o período de 2008 e 2012, ocorreu, nas atividades industriais relacionadas à celulose, ao papel e aos produtos de papel, com queda de quase $23 \%$, diminuição de $9 \%$ no refino de petróleo e álcool, de aproximadamente $34 \%$ em máquinas, aparelhos e materiais elétricos e de 31\% no setor de veículos automotores (IPARDES, 2010; BORGES, 2015).

No período de 2004 a 2012, a indústria de transformação do Estado teve crescimento de $32 \%$ em sua produção, sendo impulsionado pelas atividades madeireiras e químicos. Entre 2004 a 2011, o crescimento foi de 38\% acumulados, enquanto que o crescimento da produção física nacional foi de $10 \%$. Por esse motivo o Paraná é detentor de uma grande estrutura industrial, por ter apresentado crescimento acima da média do Brasil (FIEP, 2012; BORGES, 2015). Da quantidade de trabalhadores em atividade na indústria de transformação, o que se pode constatar foi o aumento, nos anos de 1996 a 2007, redução nos anos de 2008 e 2009, e recuperação em 2010. Tais fatos mostram que nesses momentos a indústria 
foi muito importante para geração de emprego e renda para o Estado (WASQUES, 2012).

Dados mostram que mesmo com a redução do emprego formal no setor industrial nos anos de 1985 e 2004, o percentual de mão de obra empregada na indústria de transformação cresceu de 21,5\% para 23,8\% nesse interstício, caminho oposto a nacional, que se retraiu de $25 \%$ em 1985 para menos de a $20 \%$ em 2004 . Tal fato se deve o país, no momento, passava por forte retração da atividade industrial, enquanto que o Paraná conseguiu se comportar de maneira diferente, através da adoção de políticas de fomento fiscais destinadas às empresas. Entre 1992 a 2004, tem se um aumento do percentual de participação da indústria de transformação no total de empregos formais criados, com aumento de 11\% em 1992 para 15\% em 2004 (CRUZ et al., 2007).

Dessa forma, como apontam Cruz et al (2007), o Estado estaria em um momento de industrialização, mas com esse processo ocorrendo de forma diferente entre suas mesorregiões, onde, como se era de esperar, a região Metropolitana de Curitiba novamente tem papel de proeminência na indústria de automóveis e de produtos derivados do petróleo, e as demais mesorregiões se voltam aos setores mais tradicionais, (vestuário, produtos de madeira e móveis) (TRINTIN, 2006. BRAVIN, 2015). Em questões comerciais, Wasques (2012) mostra que as exportações dos bens industriais do Estado, para os anos de 1996 e 2010, detiveram 80\% do total, enquanto que os não industriais $20 \%$. No ano de 2005 , a exportação dos produtos da indústria tem tido retração, já os não industrializados têm aumentado, fato esse que pode ser entendido pelas políticas adotadas pelo governo federal, que valorizou a moeda e provocou o encarecimento dos produtos domésticos.

A indústria nacional, a partir da década de 90 passou por um momento de descentralização, o que exerceu forte impacto sobre a industrialização de outras regiões que não a Sudeste. No Paraná, na maioria de suas microrregiões, a indústria representou $20 \%$ da geração de empregos formais, sendo que a concentração em torno da metropolitana de Curitiba não impediu que o crescimento industrial não se espalhasse para outras regiões (KUPFER, 2013; NIEHUES, 2014).

Trintin (2006) aponta que a região Metropolitana de Curitiba foi um local que gerava grande interesse por parte dos investimentos em capital, enquanto que 
as demais regiões dos Estados não eram tão receptíveis para os mesmos tipos de investimentos. Por esse motivo, e por outros, que a metropolitana de Curitiba é a região mais industrializada do Estado, enquanto que as demais se voltam mais para outros estores, principalmente o agroindustrial.

Das pesquisas expostas pode se inferir que o cenário histórico industrial paranaense passou, e passa, por um processo de modificação em sua estrutura, com o intuito de conseguir se adaptar ao ambiente econômico brasileiro e internacional cada vez mais competitivo (WASQUES, 2015; BARBOSA et al., 2015; CRUZ et al., 2007). Dessa forma, entendido o processo de industrialização do Paraná, quais as políticas adotadas ao longo dos anos para incentivar esse setor, que por muito tempo cresceu a sombra do setor agrícola e aos poucos foi ganhando notoriedade sobre seu papel como gerador de crescimento e desenvolvimento econômico, e qual tem sido o cenário industrial dos últimos anos. A próxima seção trata sobre a metodologia adotada na elaboração da pesquisa.

\section{ASPECTOS METODOLÓGICOS}

O presente trabalho, a partir de sua intenção em termos de análise do histórico de desenvolvimento da indústria nacional e do Estado do Paraná, com o objetivo de compreender como se deu esse processo, como os diversos governos, nacionais e estaduais entendiam e incentivavam o desenvolvimento desse setor e como ele pode ser utilizado como ferramenta para estimular o crescimento e o desenvolvimento econômico, através da geração de emprego, renda, descentralização e distribuição de renda, incentivo para melhorias produtivas, tecnológicas, que resultam de profissionais mais qualificados, estimulando assim direta e indiretamente melhorias educacionais para população, entre outros, se utilizaram-se duas abordagens metodológicas, a saber, uma embasada em um levantamento histórico a partir de uma revisão bibliográfica, e outra analítica estatística descritiva para a compreensão dos dados analisado.

Marconi e Lakatos (2010) apontam que o referencial teórico resultante de uma pesquisa bibliográfica tem por característica realizar um levantamento do 
material existente em meios físicos e eletrônicos, como é o caso de livros, revistas, publicações ou documentos eletrônicos que tratam do tema em análise. O presente trabalho também faz uma abordagem acerca da participação da indústria, em especial a de transformação, e como a mesma tem contribuído para a melhorias de aspectos tanto econômicos como sociais, e assim verificar sua importância para o Estado do Paraná.

A partir dos indicadores utilizados para verificar a importância da indústria para geração de emprego e renda no Paraná, será possível analisar os dados obtidos que possibilitam tal análise. Por ser uma pesquisa que adotou uma metodologia descritiva, com base em dados secundários obtidos no Instituto Paranaense de Desenvolvimento Econômico e Social. Segundo Lakatos e Marconi (1996) esse método possibilita avaliar quantitativamente quais informações estão presentes nos dados coletados, e desse modo entender quais os fatores que afetam o objeto em estudo. A série estatística utilizada é constituída por dados que têm alguma ordem de classificação, para que assim possam ser expostos em tabelas ou gráficos, e compreendidos pela variação entre anos, meses, ou outra divisão de tempo, sendo este o meio que serão apresentados os resultados da presente pesquisa.

\section{ANÁLISE DOS RESULTADOS: COMPORTAMENTO DA INDÚSTRIA NACIONAL E PARANAENSE NO PERÍODO DE 2005 A 2015}

Tendo realizada a explicação sobre o desenvolvimento industrial do estado do Paraná, essa seção aborda a análise dos dados referentes à indústria do Estado. A Tabela 1, abaixo, mostra o número de estabelecimentos industriais, total, extrativo de transformação, para as mesorregiões do Paraná. 
Tabela 1. Paraná: Média de estabelecimentos industriais em 2015

\begin{tabular}{lccc}
\hline \multicolumn{1}{c}{ Mesorregião } & Indústria total & Extrativa minerais & Indústria transformação \\
\hline Centro ocidental paranaense & 878 & 5 & 864 \\
Centro oriental paranaense & 1,749 & 63 & 1,656 \\
Centro-sul paranaense & 956 & 12 & 926 \\
Metropolitana de Curitiba & 10,912 & 224 & 10,505 \\
Noroeste paranaense & 3,101 & 42 & 3,020 \\
Norte central paranaense & 9,177 & 34 & 9,041 \\
Norte pioneiro paranaense & 1,320 & 49 & 1,244 \\
Oeste paranaense & 4,399 & 41 & 4,290 \\
Sudeste paranaense & 1,334 & 27 & 1,297 \\
Sudoeste paranaense & 2,432 & 22 & 2,377 \\
\hline
\end{tabular}

Fonte: O autor baseado em dados do Ipardes - Valor Adicionado Fiscal (2019).

O número médio de estabelecimentos do Paraná totalizou 36258 no ano de 2015. Comparando em termos de participação entre indústria de extração e de transformação, para todas as mesorregiões, o que se verifica é que a indústria de transformação é que possui o maior número de estabelecimentos, representando mais de $90 \%$ do total. Esse resultado era de se esperar visto que, dado que o processamento de um bem em outro, para consumo final ou intermediário, que é o caso da indústria de transformação, se dá em entre diversos tipos de empresas, com a produção de diversos itens, enquanto que na extrativa, alguns poucos produtos são obtidos por ela, o que mostra sua pequena participação em relação ao total (MIGLIORINI, 2006).

A Tabela 2 mostra o número observado da indústria, indústria de transformação, comércio, serviços e agropecuária. 
Tabela 2. Paraná: Estabelecimento dos setores econômicos, período 2005 - 2015 (10 mil)

\begin{tabular}{lcccccc}
\hline \multirow{2}{*}{\multicolumn{1}{c}{ Setores }} & \multicolumn{7}{c}{ Período } \\
\cline { 2 - 7 } & $\mathbf{2 0 0 5}$ & $\mathbf{2 0 0 6}$ & $\mathbf{2 0 0 7}$ & $\mathbf{2 0 0 8}$ & $\mathbf{2 0 0 9}$ & $\mathbf{2 0 1 0}$ \\
\hline Indústria & 2.58 & 2.74 & 2.83 & 2.98 & 3.11 & 3.19 \\
Extr, minerais & 0.04 & 0.04 & 0.04 & 0.04 & 0.04 & 0.04 \\
Ind, transformação & 2.51 & 2.66 & 2.75 & 2.90 & 3.03 & 3.10 \\
Comércio & 8.68 & 9.11 & 9.47 & 9.94 & 10.44 & 11.03 \\
Serviços & 7.10 & 7.35 & 7.60 & 7.94 & 8.45 & 8.92 \\
Agropecuária & 2.77 & 2.76 & 2.73 & 2.76 & 2.80 & 2.83 \\
\hline Total & 21.90 & 22.80 & 23.56 & 24.73 & 26.03 & 27.43 \\
\hline \multicolumn{1}{c}{ Setores } & $\mathbf{2 0 1 1}$ & $\mathbf{2 0 1 2}$ & $\mathbf{2 0 1 3}$ & $\mathbf{2 0 1 4}$ & $\mathbf{2 0 1 5}$ \\
\hline Indústria & 3.33 & 3.42 & 3.56 & 3.63 & 3.63 & \\
Extr, Minerais & 0.05 & 0.05 & 0.05 & 0.05 & 0.05 & \\
Ind, Transformação & 3.24 & 3.33 & 3.46 & 3.53 & 3.52 & \\
Comércio & 11.43 & 11.64 & 11.98 & 12.17 & 12.08 & \\
Serviços & 9.49 & 9.79 & 10.34 & 10.71 & 10.92 & \\
Agropecuária & 2.86 & 2.85 & 2.90 & 2.91 & 2.92 & \\
\hline Total & 28.78 & 29.49 & 30.69 & 31.46 & 31.50 \\
\hline
\end{tabular}

Fonte: $\mathrm{O}$ autor baseado em dados do Ipardes (2019).

Da Tabela 2 pode-se verificar que o número total de estabelecimentos no período de estudo apresentou crescimento de 43,82\%, indo de $219.031 \mathrm{mil} \mathrm{em}$ 2005 para 413.993 em 2015. De todos os setores, comércio e serviço foram os que possuíam maior número de estabelecimentos, sendo que, na média, representaram $40 \%$ e $33 \%$ total, respectivamente. Na indústria, de um total de $12 \%$ médio, a atividade de transformação, como esperado, possui maior participação que a de extração, com média representou $11 \%$ do total no período, enquanto que a extrativa $0,17 \%$. O setor agropecuário também participou com $11 \%$, na média, no número de estabelecimentos entre os anos em estudo.

Observa-se, porém, que ao se observar a contribuição anual de cada setor, a participação do setor agropecuário caiu 26,79\%, uma vez que em 2005 representava 12,65\% do total, e em 2015 esse valor caiu para 9,26\%. Já a indústria teve uma pequena retração em sua representatividade ao longo dos anos, indo de 11,8\% em 
2005 para 11,51\% em 2015, ou seja, queda de 2,41\%. Com exceção do setor de serviços, que apresentou aumento da participação do total anual de estabelecimentos, em muito explicado pela crise que abateu a economia brasileira que fez com que grande quantidade de empresas relacionadas essas atividades fossem abertas, dada a pequena necessita de capital e mão de obra para sua abertura, o setor industrial foi o que apresentou a menor redução, indicando que, mesmo em um período com retração da atividade econômica para o Estado, a indústria apresentou certa resistência (SILVA et al., 2016; ÁVILA, 2012, KURESK; DELGADO, 2010).

A Tabela 3, abaixo, mostra, o Valor Adicionado Fiscal, doravante VAF, dos setores industrial, agropecuário, comércio e serviços e total. O VAF é uma métrica contábil e econômica empregada para se calcular a participação dos municípios na repartição da receita advinda da arrecadação tributária das atividades relacionadas à circulação de mercadorias e também das prestações de serviços de transporte interestadual e intermunicipal, como o ICMS e o Imposto sobre Produtos Industrializados (IPI). Dessa forma, o VAF mostra o valor que se agregou nas operações de entrada e saída dos produtos ou serviços de transporte e de comunicação com o município no ano civil em análise (SEF/MG, 2016).

Tabela 3. Paraná: Valor adicionado fiscal no período 2005 a 2015 (Em R\$ bilhões*)

\begin{tabular}{cccccccc}
\hline Ano & Industria & $\begin{array}{c}\% \\
\text { ind, }\end{array}$ & Agropecuária & $\begin{array}{c}\% \\
\text { Agrop }\end{array}$ & Com/Ser & $\%$ comer/serv & Total \\
\hline 2005 & 54.98 & 52.44 & 17.44 & 16.64 & 32.14 & 30.66 & 104.84 \\
2006 & 56.18 & 52.47 & 16.94 & 15.82 & 33.59 & 31.37 & 107.08 \\
2007 & 58.23 & 50.03 & 20.92 & 17.97 & 36.90 & 31.71 & 116.39 \\
2008 & 64.32 & 48.31 & 24.97 & 18.75 & 43.32 & 32.54 & 133.15 \\
2009 & 72.22 & 47.94 & 27.51 & 18.26 & 49.95 & 33.16 & 150.65 \\
2010 & 73.83 & 47.71 & 26.37 & 17.04 & 54.00 & 34.89 & 154.75 \\
2011 & 90.90 & 46.45 & 33.92 & 17.33 & 70.44 & 35.99 & 195.69 \\
2012 & 90.09 & 45.01 & 38.23 & 19.10 & 71.29 & 35.62 & 200.13 \\
2013 & 102.90 & 44.18 & 44.05 & 18.91 & 85.60 & 36.75 & 232.91 \\
2014 & 107.19 & 43.23 & 48.33 & 19.49 & 91.73 & 37.00 & 247.95 \\
2015 & 111.08 & 43.73 & 52.64 & 20.72 & 89.60 & 35.27 & 254.03 \\
\hline
\end{tabular}

Fonte: O autor baseado em dados do Ipardes - Valor Adicionado Fiscal (2019).

*Valores deflacionados pelo IGP-DI tendo como ano base 2015. 
Pode se observar que, mesmo com os setores de comércio e serviços possuindo o maior número de estabelecimentos, é a indústria o maior gerador do VAF estadual, em todo o período. Até o ano de 2007, a indústria gerava mais de 50\% do total do VAF do Estado, e após essa data, esse percentual foi diminuindo, chegando em seu mínimo no ano de 2014, representando 43,23\%, mas com pequeno crescimento no em 2015, indo para 43,73\%. De modo absoluto, houve redução de geração do VAF pelo setor, que foi de $\mathrm{R} \$ 52,44$ bilhões em 2005 para $\mathrm{R} \$ 43,73$ bilhões em 2015, ou seja, redução de 16,61\%.

Dado o período em estudo possuir uma crise internacional de grandes proporções, era de se esperar que houvesse crescimento dos setores de comércio e de serviços, que tiveram crescimento em sua participação a cada ano, tendo seu pico em 2014, ano que chegou a representar $37 \%$ do total do VAF gerado no Estado, crescimento de $15,05 \%$, e em termos de arrecadação cresceu 178,78\%, indo de um total de $R \$ 32,14$ bilhões em 2005 para $R \$ 89,6$ bilhões em 2015 . No total o setor agropecuário teve crescimento em sua participação do VAF obtido, pois foi de um percentual de 16,64 para 20,72 , ou seja, crescimento de $24,56 \%$, e em termos de arrecadação foi de $\mathrm{R} \$ 17,44$ bilhões para 52,64 bilhões no período, com crescimento de mais de 200\%(SILVA et al., 2016).

Desagregando para as microrregiões, o Gráfico 1, abaixo, mostra a arrecadação do VAF obtido no período de 2005 a 2015.

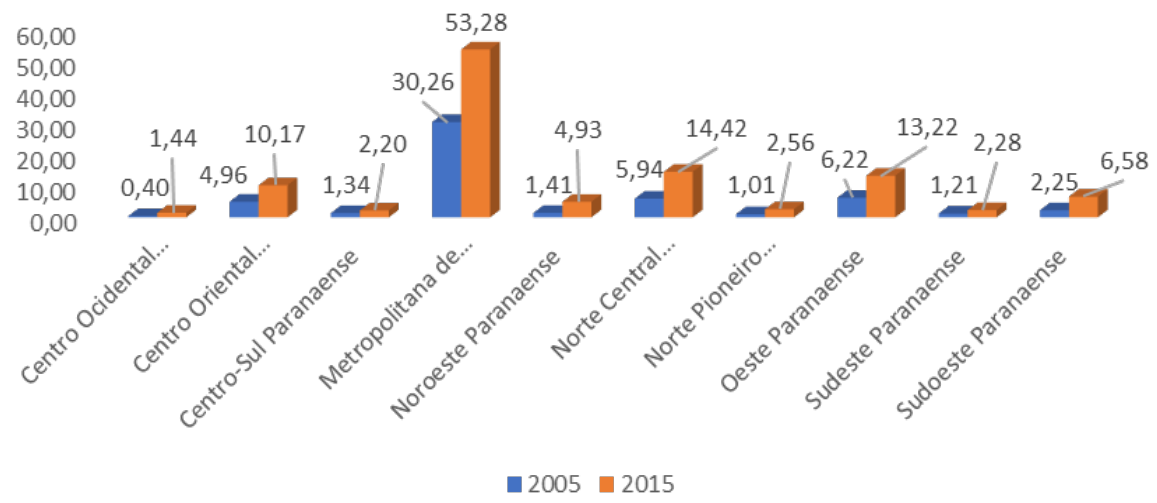

*Valores deflacionados pelo IGP-DI tendo como ano base 2015.

Gráfico 1. Paraná: Valor Adicionado Fiscal da Indústria, para as mesorregióes paranaenses no período 2005 a 2015 (em R\$ bilhões*).

Fonte: $\mathrm{O}$ autor baseado em dados do Ipardes - Valor Adicionado Fiscal (2019). 
Do total do VAF gerado pela indústria, para o ano de 2005 e 2015, verificouse um aumento de $102 \%$ do total arrecadado, uma vez que no primeiro ano o valor obtido foi de $\mathrm{R} \$ 54.99$ bilhões, e no fim do período, foi para $\mathrm{R} \$ 111.08$ bilhões. Ao se observar as mesorregiões que compõem o Estado, a região Metropolitana de Curitiba se destaca, com uma VAF de R $\$ 30,26$ bilhões no ano de 2005, e 53,28\% em 2015. Não obstante, a grande participação dessa mesorregião para o VAF do Estado, pode-se perceber que sua contribuição no total caiu entre esses dois anos, dado que em 2005, 55\% do VAF do Estado era dessa mesorregião, já em 2015 esse percentual caiu para 48\%. Esse fato evidencia que entre esses anos, houve uma desconcentração da indústria no Estado, espalhando-se pelas demais regiões (BORGES, 2015).

Depois da metropolitana de Curitiba, o maior VAF obtido foi do oeste paranaense, que teve aumento percentual na arrecadação no período, seguido do norte central paranaense, que, em 2005, ocupou a terceira colocação em termos de arrecadação, mas em 2015, foi para segunda posição, indo de uma arrecadação de $\mathrm{R} \$ 5,94$ bilhões para $\mathrm{R} \$ 14,42$. Verifica-se que todas as mesorregiões apresentaram aumento na arrecadação, mas das dez, três delas, a saber, a Metropolitana de Curitiba, a Centro Sul e a Sudeste, tiveram redução em sua participação da arrecadação do Estado, o que evidencia a redução no número da produção industrial nessas regiões, mostrando que houve migração dos estabelecimento industriais no período.

Tabela 4. Paraná: emprego (RAIS), total, indústria e indústria de transformação, período 2005 a 2015

\begin{tabular}{ccccccccc}
\hline \multirow{2}{*}{ Período } & \multicolumn{7}{c}{ Emprego por setor } \\
\cline { 2 - 8 } & Indústria & Var \% & Comércio & Var \% & Serviços & Var \% & Agropecuária & Var \% \\
\hline 2005 & 14,835 & - & 25,184 & - & 29,845 & - & 962 & - \\
2006 & 23,697 & $60 \%$ & 21,205 & $-16 \%$ & 33,115 & $11 \%$ & 1,245 & $29 \%$ \\
2007 & 46,524 & $96 \%$ & 30,502 & $44 \%$ & 30,996 & $-6 \%$ & 5,753 & $362 \%$ \\
2008 & 22,765 & $-51 \%$ & 33,067 & $8 \%$ & 35,686 & $15 \%$ & 6,080 & $6 \%$ \\
2009 & 12,993 & $-43 \%$ & 22,755 & $-31 \%$ & 27,377 & $-23 \%$ & 4,381 & $-28 \%$ \\
2010 & 41,116 & $216 \%$ & 36,110 & $59 \%$ & 49,791 & $82 \%$ & 2,209 & $-50 \%$ \\
2011 & 23,691 & $-42 \%$ & 30,521 & $-15 \%$ & 47,793 & $-4 \%$ & 508 & $-77 \%$ \\
2012 & 12,093 & $-49 \%$ & 25,935 & $-15 \%$ & 31,959 & $-33 \%$ & 346 & $-32 \%$ \\
2013 & 12,831 & $6 \%$ & 25,873 & $0 \%$ & 36,368 & $14 \%$ & 1,419 & $310 \%$ \\
2014 & 8,894 & $-31 \%$ & 12,260 & $-53 \%$ & 29,389 & $-19 \%$ & 555 & $-61 \%$ \\
2015 & 46,597 & $424 \%$ & 13,044 & $6 \%$ & 4,659 & $-84 \%$ & 2,516 & $353 \%$ \\
\hline
\end{tabular}

Fonte: O autor baseado em dados do Ipardes - Valor Adicionado Fiscal (2019). 
Em termos de geração de emprego no Estado, ao se analisar os principais setores da economia do Estado, se observa que os setores industrial e agropecuário tiveram aumento percentual de 214 e 161, respectivamente, enquanto que comércio e serviço tiveram redução percentual de 48,21 e 84,39, respectivamente. Observa-se também que comércio e serviços são os que, com exceção do ano de 2015, foram os que mais empregam, com uma trajetória inconstante no período, com picos de mínimo, como nos anos de 2014, e de picos de máximo, como no ano de 2010 para o comércio e serviços, em que tiveram um total empregado de 36.110 e 49.791 mil trabalhadores, respectivamente.

Já a indústria, que admitia quase a metade do que empregava o setor de serviços, no ano de 2005, em 2015 foi o setor com o maior número de empregado, com um total 46.597. Destaca-se também que nesse setor se verificaram os maiores choques entre anos, em termos de variação, que chegou a ter um aumento de $96 \%$ entre 2007 e 2006, e de $216 \%$ entre 2010 e 2009 e $424 \%$ entre 2014 e 2015 mas com reduções de 51\% entre 2008 e 2007 e de $49 \%$ entre 2012 e 2011, o que evidencia a grande fragilidade desse setores ao ambiente econômico e político.

A Tabela 6 apresenta o rendimento médio da indústria (extrativa e de transformação), comércio, serviços e agropecuário, com o objetivo de comparar a remuneração obtida por esses setores, e qual seu comportamento entre 2005 a 2015.

Tabela 5. Paraná: Rendimento médio*, valores deflacionados a preços constantes, período de 2005 a 2015

(Continua)

\begin{tabular}{cccccccc}
\hline Ano & Total & Indústria & Extr mineral & Ind. trans. & Comércio & Serviços & Agropecuária \\
\hline 2005 & 1049.85 & 947.39 & 1738.10 & 2020.50 & 781.89 & 651.55 & 1228.39 \\
2006 & 1100.39 & 1011.33 & 2528.69 & 2031.97 & 583.20 & 689.50 & 1860.47 \\
2007 & 1131.92 & 1062.60 & 2712.65 & 2048.09 & 589.15 & 741.84 & 1984.30 \\
2008 & 1214.32 & 1160.79 & 2830.88 & 2056.81 & 611.75 & 838.44 & 2116.85 \\
2009 & 1458.71 & 1252.72 & 2598.04 & 2060.46 & 734.31 & 877.38 & 1944.98 \\
2010 & 1418.95 & 1377.01 & 3914.02 & 2064.66 & 541.33 & 997.33 & 2929.03 \\
2011 & 1667.93 & 1520.98 & 1939.46 & 2083.24 & 1210.59 & 1099.72 & 1424.61 \\
2012 & 1785.19 & 1699.11 & 1949.79 & 2079.92 & 1335.88 & 1175.32 & 1449.64 \\
2013 & 2021.54 & 1832.20 & 1956.81 & 2100.62 & 1478.89 & 1317.54 & 1467.69 \\
\hline
\end{tabular}




\begin{tabular}{cccccccc}
\hline \multicolumn{1}{c}{ Ano } & Total & Indústria & Extr Mineral & Ind. Trans. & Comércio & Serviços & Agropecuária \\
\hline 2014 & 2238.55 & 1993.98 & 1945.63 & 2098.35 & 1629.41 & 1443.23 & 1455.82 \\
2015 & 2305.07 & 2196.88 & 2046.59 & 2095.15 & 1677.89 & 1573.28 & 1549.91 \\
\hline
\end{tabular}

Fonte: O autor baseado em dados do Ipardes - Valor Adicionado Fiscal (2019).

*Valores deflacionados pelo IGP-DI tendo como ano base 2015.

De início se percebe que os maiores rendimentos são, para os primeiros anos, na indústria de transformação, de extração mineral e agropecuária e, em termos reais, em todo o período, a indústria de transformação e extração foram as que melhor remuneraram seus trabalhadores, não obstante o crescimento real foi maior nos setores comercial e serviços. Como era de se esperar, dada a demanda por profissionais com mais qualificação que o setor industrial apresenta, maiores seriam os salários desses funcionários, evidenciando mais uma vez o potencial que esse setor tem para gerar externalidade positiva para sociedade, em termos não somente de geração de renda, mas impactando positivamente outras áreas, como distribuição de renda, aumento de renda, estímulos à qualificação profissional na região onde tal setor se desenvolve, entre outros (BRAVIN et al, 2015).

Com vistas a se analisar melhorias sociais, em termos de melhor distribuição de renda, avaliou-se o comportamento do índice de Gini para os anos de 1991, 2000 e 2010, índice esse que indica o grau de concentração de renda em uma região, de modo que, quanto mais próximo de zero, melhor é sua distribuição (MATOS, 2005; CANO, 2012). De acordo com dados do Ipardes (2019), percebe-se o índice de Gini, que antes se encontrava em 0,6 em 1991 e em 2000, caiu para 0,53 em 2010, mostrando uma melhora em termos na distribuição de renda no Estado, uma vez que, quando mais próximo de zero melhor é o modo como a renda é distribuída. Uma economia que apresenta mais emprego, maior é a renda presente, sendo que esta ocorre com menor concentração dada a diversidade de empresas e empregos existentes e, como foi verificado, a indústria tem desempenhado um papel de destaque na geração de emprego e de número de estabelecimento no Estado do Paraná (MATOS, 2005; LOURENÇO; ROMERO, 2002)

A Tabela 6 mostra a distribuição do IDH, indicador de qualidade de vida composto pela medição de três esferas sociais, a saber: renda, educação e expectativa 
de vida, e diferente do índice de Gini, quanto maior próximo de zero, pior a situação da região (IPEA, 2017, MEDERIOS, 2012).

Tabela 6. IDH das mesorregiões paranaenses para os anos de 1991, 2000 e 2010

\begin{tabular}{lccc}
\hline Mesorregiões & $\mathbf{1 9 9 1}$ & $\mathbf{2 0 0 0}$ & $\mathbf{2 0 1 0}$ \\
\hline Noroeste paranaense & 0,4431 & 0,6011 & 0,7052 \\
Centro ocidental paranaense & 0,4202 & 0,5839 & 0,7027 \\
Norte central paranaense & 0,4600 & 0,6141 & 0,7136 \\
Norte pioneiro paranaense & 0,4479 & 0,5940 & 0,7016 \\
Centro oriental paranaense & 0,4153 & 0,5821 & 0,6890 \\
Oeste paranaense & 0,4627 & 0,6215 & 0,7174 \\
Sudoeste paranaense & 0,4143 & 0,6026 & 0,7156 \\
Centro-sul paranaense & 0,3361 & 0,5193 & 0,6537 \\
Sudeste paranaense & 0,3900 & 0,5501 & 0,6788 \\
Metropolitana de Curitiba & 0,4255 & 0,5779 & 0,6931 \\
\hline
\end{tabular}

Fonte: PNUD (2019).

Ao analisar as mesorregiões, o que se percebe é que todas tiveram melhorias entre 1991 a 2010. As que tiveram as melhores posições, no ano de 1991 foram o Oeste paranaense, com um IDH de 0,4627 , seguida da Norte central $(0,4600)$, Norte pioneiro $(0,4479)$ e Noroeste $(0,4431)$. Já no ano de 2010 ainda foram o Oeste paranaense, com IDH de 0,7174 , seguido da Oeste $(0,7156)$, da Norte central $(0,7136)$ e Noroeste $(0,7052)$.

Ao se fazer uma relação da Tabela 6 com a Tabela 1 (média de estabelecimentos por mesorregião) pode-se perceber que com poucas exceções as mesorregiões com mais indústrias são as que possuem os maiores IDH. Destaca-se que a metropolitana de Curitiba, mesmo não tendo o maior IDH entre as mesos, e sendo a mais industrializada, pelo fato de que ela é formada por um conjunto de municípios que possui alto grau de industrialização e por municípios com baixo grau, o que pode ser uma explicação para não possuir o maior IDH do Estado. 


\section{CONSIDERAÇÕES FINAIS}

O objetivo da presente pesquisa foi analisar como a indústria paranaense, principalmente a de transformação, influenciava o crescimento e desenvolvimento do Estado, pela ótica tanto econômica como social, entre os anos de 2005 a 2015. Para alcançar o proposto, foi analisado, a partir de uma revisão bibliográfica, o processo histórico de formação da indústria do Estado do Paraná, que teve suas origens servindo de atividade de apoio à agricultura e, com o passar do tempo, por meio da ação de políticas públicas, começou a se desenvolver de modo autônomo.

A análise descritiva a partir dos dados mostrou que a indústria paranaense apresentou crescimento no número de estabelecimento entre 2005 e 2015 em todos os três setores, e na indústria, como esperado, além de ter crescimento, esse foi maior na indústria de transformação do que na extrativa, dado que esse setor, por ser composto por um grande conjunto de atividades, demanda mais mão de obra e capital físico que a extrativa.

Ainda para o Estado, viu-se que em termos de arrecadação, medido pelo Valor Adicionado Fiscal, a indústria é que apresentou em todo o período a maior arrecadação entre os setores. Não obstante, os setores de comércio e serviços foram os que apresentaram maior crescimento percentual no período, isso pode ser explicado pois, dada a grande crise internacional que abateu o cenário internacional, houve forte retração da atividade econômica, e esse setores, por demanda, poucos recursos financeiros e recursos humanos, se expandiram fortemente nesse interstício.

Analisando o VAF por mesorregião a Metropolitana de Curitiba se destaca em todo o período, com participação de mais de 50\% da arrecadação estadual em 2005, e mesmo com queda, ainda detinha $48 \%$ da arrecadação em 2015. Em termos de emprego, a indústria teve crescimento de $214 \%$ da geração de emprego. Já em termos de rendimento, a indústria de transformação e de extração foram as que melhor remuneraram seus trabalhadores, mesmo que crescimento real tenha sido maior nos setores comercial e serviços. Os indicadores sociais apresentaram melhoria no período, o que indica que alguns fatores os influenciaram positivamente, e nesse rol de determinantes a indústria, pelo seu potencial de criação e geração de emprego, renda, dinamização da região ao seu redor, foi fundamental para essa melhoria.

Dessa forma, o que se pode inferir da presente pesquisa é que mesmo 
que o histórico de desenvolvimento industrial estadual ocorreu de forma letárgica, a indústria se mostrou como um setor de grande potencial, e de fato verificado pela pesquisa, com gerador de dinamização e desenvolvimento socioeconômico, uma vez que se viu ao longo da pesquisa, que a indústria Estado do Paraná foram fundamentais para o crescimento e desenvolvimento econômico, dado que no Estado foi o setor com maior arrecadação tributária, geração de emprego e maiores rendimentos.

\section{REFERENCIAS}

ÁVILA, M. Impacto da crise no mercado de trabalho da indústria de transformação: uma análise das horas trabalhadas e do emprego. [s.l.; s.n.], 2012.

BÔAS, H. C. V. A indústria extrativa mineral e a transição para o desenvolvimento sustentável. Rio de Janeiro: [s.n.], 2011.

\section{BORGES, P. R. S. Inserção da região centro ocidental no cenário econômico} do Paraná: atividades industriais. 2015. Tese (Doutorado em Geografia) Universidade Estadual de Maringá, UEM, 2015.

BRAVIN, N. J.R; GÓES, S. L. V; BRAVIN, S. M. R. A FORMAÇÃO INDUSTRIAL NO PARANÁ: do desenvolvimento e formação de aglomerados a distribuição desigual no espaço. Revista Eletrônica de Geografia, v.7, n.18, p. 48-66, set. 2015.

CANO, W. A desindustrialização no Brasil. IE/Unicamp, Campinas, n. 200, Jan. 2012.

FIEP - Federação das Indústrias do Estado do Paraná. Panorama Industrial do Paraná, 2015. Disponível em: http://www.fiepr.org.br/observatorios/ uploadAddress/Panorama_Industrial_2015[63113].pdf. Acesso em: 25 abr. 2019

IPARDES - Instituto Paranaense de Desenvolvimento Econômica e Social. As características do crescimento industrial paranaense, 2010. Disponível em: http://www.ipardes.gov.br/biblioteca/docs/NT_05_crescimento_indl_paranaense. pdf. Acesso em: 25 abr. 2019 
IPARDES - Instituto Paranaense de Desenvolvimento Econômica e Social. Base de Dados. Disponível em: http://www.ipardes.pr.gov.br/imp/index.php. Acesso em: 25 abr. 2019

IPARDES - Instituto Paranaense de Desenvolvimento Econômica e Social. Cenários da economia paranaense; 1987 - 1991. Disponível em: http://www.ipardes.gov. br/. Acesso em: 25 abr. 2019.

IPEA - Instituto de Pesquisa Econômica Aplicada. Desenvolvimento Humano para além das médias. 2017. Disponível em: https://www.undp.org/content/dam/ brazil/docs/IDH/desenvolvimento-alem-das-medias.pdf. Acesso em: 25 abr. 2019.

KUPFER, D. Dez anos de políticas industrial. Valor Econômico, 2013. Disponível em: http://www.valor.com.br/opiniao/3189592/dez-anos-de-politica-industrial. Acesso em: 05 abr. 2019.

KURESK, R; DELGADO, P. R. Importância do Setor De Serviços no Estado do Paraná. Revista Paranaense De Desenvolvimento, Curitiba, n.118, p.139-158, jan./jun. 2010

MARCONI, M. A; LAKATOS, E. M. Fundamentos de metodologia científica. 7.ed. São Paulo: Atlas, 2010.

LOEFFLER, W. Aspectos da indústria paranaense: 1930 - 1970. 2009.

Dissertação (Mestre em Histórica Econômica) - Universidade de São Paulo (USP), 2009.

LOURENÇO, G. M. A economia paranaense em tempos de globalização. Curitiba: Ed. do Autor. 2003.

LOURENÇO, G. M. ROMERO. M. Indicadores Econômicos. In: ECONOMIA empresarial: Fae Business School. Curitiba: Associação Franciscana de Ensino Senhor Bom Jesus, 2002.

MATOS, J. D. Distribuição de renda: fatores condicionantes e comparação entre as regiões metropolitanas pesquisadas pela PED. 62. ed. Porto Alegre: FEE, 2005.

MIGLIORINI, S. M. S. Indústria Paranaense: Formação, transformação econômica 
a partir da década de 1960 e distribuição espacial da indústria no início do século XXI. Revista Geografar (UFPR), v. 1, p. 62-80, 2006.

\section{NADOLNY, S. A importância econômica do mate para o Estado do Paraná.} Curitiba: UFPR, 2014.

NIEHUES, L. G. A industrialização do Paraná: abordagens de um processo de desenvolvimento concentrado. In: XXX SEMANA DE GEOGRAFIA DA UEL 30.; COLÓQUIO DE GEOGRAFIA(S) TERRITORIAL(AIS) PARANAENSE(S) 2,2014, Londrina. 2014. Anais [...]. Londrina, 2014.

OLIVEIRA, D. Urbanização e Industrialização no Paraná. SEED: Curitiba. 2001.

PNUD - PROGRAMA DAS NAÇÕES UNIDAS PARA O DESENVOLVIMENTO. Atlas do desenvolvimento humano no Brasil 2013. Disponível em: http://www.br.undp. org/content/brazil/pt/home/idh0.html. Acesso em: 25 abr. 2019.

SECRETARIA DA FAZENDA, MG. Valor Adicionado Fiscal. Disponível em: www. fazenda.mg.gov.br. Acesso em: em: 25 abr. 2019.

SILVA, C. M; MENEZES FILHO, N; KOMATSU, B. Uma Abordagem sobre o setor de serviços na economia brasileira. São Paulo: Insper, 2016.

TRINTIN, J. G. A nova economia paranaense: 1970 - 2000. Maringá: Ed. da Eduem, 2006.

VERRI. E.J. O Desenvolvimento Recente à Indústria Paranaense. 1998.

Dissertação (Mestrado em Economia) - Universidade Estadual de Maringá, UEM, 1998.

WASQUES, R. N. O Fenômeno da Desindustrialização: uma análise do caso brasileiro na década de 2000. Economia Ensaios, 2011. Disponível em: http:// www.seer.ufu.br/index.php/revistaeconomiaensaios/article/view/17366. Acesso em: 08 abr. 2019. 